\title{
Analisis Kepuasan Optimalisasi Kinerja Jaringan Berbasis Load Balancing dan Wifi-Offload Menggunakan Uji T Paired (Studi Kasus pada UPN Veteran Jakarta)
}

\author{
Fajar Rahayu I Mariati ${ }^{1, *}$, Mohammad Rachman Waluyo ${ }^{2}$, Teris Ekamila Wahyundari ${ }^{3}$ \\ ${ }^{1,3}$ Program Studi Teknik Elektro, Universitas Pembangunan Nasional Veteran Jakarta, 12450, Indonesia \\ ${ }_{2}^{2}$ Program Studi Teknik Industri, Universitas Pembangunan Nasional Veteran Jakarta, 12450, Indonesia \\ *E-mail : fajarrahayu@upnvj.ac.id
}

\begin{abstract}
Abstrak
Penggunaan WiFi merupakan salah satu teknologi yang tepat untuk melakukan pembelajaran di lingkungan universitas. Karena itu, sarana dan prasarana telekomunikasi haruslah mumpuni dalam memenuhi kebutuhan untuk berkomunikasi dengan cepat, dan tanpa batas. Semua pengguna jaringan WiFi di lingkungan Fakultas Teknik UPN "Veteran" Jakarta, dapat berkomunikasi tanpa lagi menunggu antrian. Tantangan utama pada sistem komunikasi nirkabel adalah sumber daya yang tidak dapat mengimbangi akan lonjakan trafik yang terjadi akibat penggunaannya, maka fenomena bottleneck terjadi. Pada ruang dosen Fakultas Teknik UPN Veteran Jakarta belum terdapat hotspot yang mumpuni dalam menyediakan jaringan wifi yang menyebabkan surfing. Oleh karena itu solusi pemerataan trafik yang ada pada setiap segmen berbasiskan data pengguna Wifi dan jumlah user yang mengakses setiap harinya dan orientasi akhirnya bagaimana kepuasan optimalisasi kinerja jaringan berbasis Load Balancing dan Wifi-Offload menggunakan Uji T Paired. Dari pengujian dengan SPSS untuk Uji Normalitas didapat nilai $\mathrm{Sig}=0,434>0,05$ dan 0,344 $>0,05$ berarti sebaran datanya normal sedangkan untuk pengujian $t$ Test didapat penambahan fasilitas hotspot terjadi peningkatan sebesar 99,323, peningkatan sebesar itu secara statistik bisa dikatakan benar-benar meningkat maka diperoleh nilai $t$ sebesar $-3,279$ dengan nilai signifikansi $=0,003<0.05$ berarti ada perbedaan. Bisa disimpulkan bahwa sebaiknya diberikan fasilitas tambahan mempengaruhi peningkatan rata-rata pemakaian sebesar 99,323 dimana peningkatan yang terjadi antara 37,464 sd 161,181.
\end{abstract}

Kata kunci : Industri 4.0, Wifi-Offload, Bottleneck, Surfing, Data Traffic, Hotspot, Load Balancing, Uji T Paired

Pendahuluan

Kebutuhan manusia pada era globalisasi sekarang terhadap informasi dan komunikasi menjadi pendorong terjadinya kemajuan yang sangat pesat pada sarana informasi dan komunikasi [1]. Hal tersebut menyebabkan, Terjadinya peningkatan dan pertumbuhan layanan data secara global seiring peningkatan penggunaan perangkat elektronik [2]. Jaringan internet berada pada berbagai sektor dan digunakan dalam berbagai aktifitas, terlebih lagi pada tren otomasi, industri 4.0 [3]. Hal tersebut mendorong perusahaan untuk mampu bersaing secara global. Dengan cara menunjukkan keunggulan dari produk maupun jasa dibandingkan dengan kompetitornya [4]. Kualitas termasuk ke dalam aspek yang harus menjadi titik pusat perhatian perusahaan dalam dunia bisnis [5]. Tantangan utama pada sistem komunikasi nirkabel adalah sumber daya yang tidak dapat mengimbangi akan lonjakan-lonjakan trafik yang terjadi akibat penggunaan. Apabila sumber daya terutama infrastruktur yang ada saat ini kurang siap menerima lonjakan tersebut, maka fenomena bottleneck dapat terjadi. Lonjakan trafik ini bisa diatasi dengan menggunakan teknologi WiFi. Perangkat elektronik yang dapat menggunakan teknologi Wi-Fi (Sumber jaringan) yaitu melalui hotspot. Hotspot ini mempunyai titik jaringan Hotspot dan memiliki jarak 20 meter di dalam ruangan dan luar ruangan. Lingkup dari hotspot dapat mencakup suatu ruangan dengan dinding yang terhalang oleh gelombang radio sekitar $20 \mathrm{~m} 2$. Hotspot ini dapat diposisikan secara saling berdekatan jaraknya. Pada ruang dosen Fakultas Teknik Universitas 
Pembangunan Nasional (UPN) Veteran Jakarta, belum terdapat hotspot mumpuni dalam menyediakan jaringan wifi. Para dosen sering sekali mengalami putus koneksi internet pada saat sedang surfing untuk pengajaran. Permasalahan ini dirasa sedikit mengganggu jalannya pengajaran secara daring, juga sedikit mengganggu dalam hal akses materi pengajaran.

Teknologi WiFi sebenarnya sudah diterapkan sejak lama. Pada [6-7] suatu platform perusahaan telekomunikasi berkelas dapat mendukung standar Wi-Fi dan Seluler, serta diinovasikan untuk membangun kerjasama antara jaringan Wi-Fi dengan jaringan Seluler yang aman. Load Balancing antar GW sangat efektif digunakan untuk NGN Mobile yang berbasis IP. Dalam menghindari GW yang mengalami kepadatan atau kemacetan sehingga dapat berkontribusi untuk mengoptimalkan kinerja jaringan secara keseluruhan [8-9]. Pada penelitian [10] penulis menawarkan solusi pemerataan trafik yang ada pada setiap segmen dengan menggunakan metode pemerataan trafik, keuntungan dari penggunaan pemerataan trafik yaitu:

1. Peningkatkan kinerja sistem secara keseluruhan

2. Beban trafik yang merata

3. Waktu respon lebih pendek

4. Throghput lebih tinggi

5. Jaringan lebih siap menerima perkembangan atau penambahan beban

Dalam mengatasi ketimpangan trafik di ruang dosen Fakultas Teknik. Tujuan dari penelitian ini adalah mengatasi permasalahan bottle neck pada jaringan, memberikan pemerataan trafik komunikasi serta menjaga kualitas jaringan telekomunikasi pada lingkungan Fakultas Teknik UPN Jakarta, sehingga dengan penelitian ini mampu mengatasi permasalahan pada penggunaan trafik yang tidak merata, serta dapat memberikan kontribusi yang kuat untuk pengembangan teknologi di Fakultas Teknik khususnya untuk pengguna Dosen yang mengakses jaringan wifi di Ruang Dosen lantai 2.

\section{Metode Penelitian}

Penelitian ini menggunakan data trafik yang terekam oleh pusat telekomunikasi Universitas. Adapun data yang diambil merupakan data trafik serta data pengguna baik sebelum dipasang hotspot, dan setelah dipasang hotspot pada Ruangan dosen Lantai 2 Fakultas Teknik UPN Jakarta. Adapun posisi hotspot terpasang ada di lantai 2. Penelitian load balancing ini dilakukan 4 proses.

1. Metadata dilakukan dengan 3 langkah, pertama pengamatan jaringan yang ada di UPN dan Fakultas Teknik dan bagaimana layanan Internet di Fakultas Teknik, langkah selanjutnya sistem merancang load balancing. Langkah kedua dengan wawancara, proses wawancara terkait bagaimana rancangan jaringan di Fakultas Teknik.

2. Analisis jaringan dilakukan untuk melihat kondisi Wifi saat ini. Analisis ini dilihat topologi jaringan yang digunakan.

3. Perancangan load balancing dilakukan dari hasil analisis jaringan. Design rancangan akan menghasilkan skema yang cocok untuk load balancing,

4. Test sistem load balancing. Pengujian metadata meliputi bagaimana keberhasilan sistem load balancing apakah berhasil jika koneksi off dan bagaimana jaringan cadangan berjalan untuk menganti koneksi utama yang off (Keseimbangan koneksi dan kondisi IP).

\section{Populasi}

Populasi penelitian adalah semua dosen di Fakultas Teknik dengan dosen 30, dikarenakan populasi kurang dari 100 orang, maka sesuai teori, sample penelitian sama dengan populasi penelitian.

\section{Pengumpulan Data}

Pengumpulan data penelitian ini terdiri dari data sekunder dan data primer. 


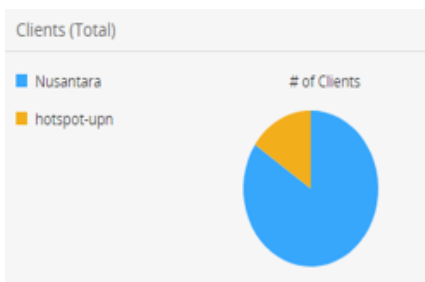

Gambar 1. Data Pengguna Wifi

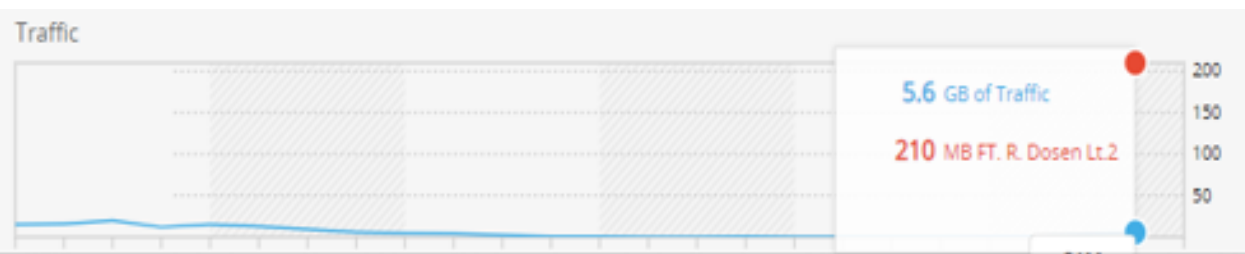

Gambar 2. Analisis jumlah user yang terlayani di Ruang Dosen lantai 2 Fakultas Teknik
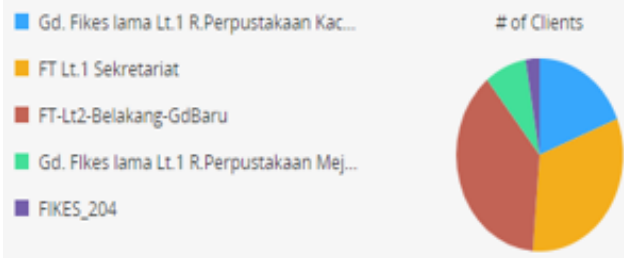

Gambar 3. Data Jaringan Wifi

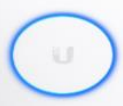

Gambar 4. Hotspot yang dipasang di Ruang Dosen lantai 2

\section{Hasil Penelitian}

\section{Pengolahan Data}

Semua proses uji instrumen dalam penelitian ini tidak dilakukan secara perhitungan manual tetapi menggunakan program IBM SPSS 25. Data yang digunakan adalah data traffic sebelum penambahan hotspot yaitu bulan Mei - Juni (MJ) dan data traffic penambahan hotspot yaitu di bulan Juli - Agustus (JA)

\section{Demografi}

Demografi penelitian ini adalah semua dosen yang di lantai 2 yang berjumlah 30 orang.

Tabel 1. Tanggal 4 Agustus

TANGGAL 4 AGUSTUS ( PUKUL 13.00-18.00)

\begin{tabular}{|c|c|c|c|c|c|}
\hline \multirow{2}{*}{ No } & \multirow{2}{*}{ JAM } & \multicolumn{2}{|c|}{ CLIENT } & \multicolumn{2}{c|}{ TRAFFIC } \\
\cline { 3 - 6 } & & ALL USERS & $\begin{array}{c}\text { USER } \\
\text { DETAIL }\end{array}$ & $\begin{array}{c}\text { ALL } \\
\text { USERS }\end{array}$ & $\begin{array}{c}\text { USER } \\
\text { DETAIL }\end{array}$ \\
\hline 1. & 13.00 & 48 & - & $3.1 \mathrm{~GB}$ & - \\
\hline $\mathbf{2 .}$ & 14.00 & 50 & - & $1.4 \mathrm{~GB}$ & - \\
\hline $\mathbf{3}$. & 15.00 & 23 & - & $0.85 \mathrm{~GB}$ & - \\
\hline 4. & 16.00 & 26 & - & $0.98 \mathrm{~GB}$ & - \\
\hline $\mathbf{5 .}$ & 17.00 & 37 & - & $1 \mathrm{~GB}$ & - \\
\hline 6. & 18.00 & 36 & - & $1.6 \mathrm{~GB}$ & - \\
\hline
\end{tabular}

Tabel 2. Tanggal 5 Agustus

TANGGAL 5 AGUSTUS ( PUKUL 04.00 - 11.00 )

\begin{tabular}{|c|c|c|c|c|c|}
\hline \multirow{2}{*}{ NO } & \multirow{2}{*}{ JAM } & \multicolumn{2}{|c|}{ CLIENT } & \multicolumn{2}{c|}{ TRAFFIC } \\
\cline { 3 - 6 } & & ALL USER & $\begin{array}{c}\text { USER } \\
\text { DETAIL }\end{array}$ & ALL USERS & $\begin{array}{c}\text { USER } \\
\text { DETAIL }\end{array}$ \\
\hline $\mathbf{1 .}$ & 04.00 & 9 & - & $1 \mathrm{~GB}$ & - \\
\hline $\mathbf{2 .}$ & 05.00 & 11 & - & $1.1 \mathrm{~GB}$ & - \\
\hline $\mathbf{3 .}$ & 06.00 & 18 & - & $0.45 \mathrm{~GB}$ & - \\
\hline $\mathbf{4 .}$ & 07.00 & 13 & - & $0.31 \mathrm{~GB}$ & - \\
\hline $\mathbf{5 .}$ & 08.00 & 25 & - & $0.43 \mathrm{~GB}$ & - \\
\hline $\mathbf{6 .}$ & 09.00 & 22 & - & $0.7 \mathrm{~GB}$ & - \\
\hline $\mathbf{7 .}$ & 10.00 & 21 & - & $0.37 \mathrm{~GB}$ & - \\
\hline $\mathbf{8 .}$ & 11.00 & 0 & - & $0.49 \mathrm{~GB}$ & $30 \mathrm{~KB}$ \\
(FT.R.DOSEN)
\end{tabular}


Tabel 3. Mei 2019

\begin{tabular}{|c|c|c|c|c|c|}
\hline \multirow{2}{*}{ Na } & \multirow{2}{*}{ TANGGAL } & \multicolumn{2}{|c|}{ CLIEIT } & \multicolumn{2}{|c|}{ TRurnc } \\
\hline & & AIL TSERS & TSER DETAII & AIL TSERS & TEER DETAII \\
\hline 1 & 1 X11 2019 & 645 & . & $120 \mathrm{~GB}$ & . \\
\hline 2 & $2 \mathrm{Xti} 2019$ & 575 & . & $190 \mathrm{CB}$ & . \\
\hline 3. & 3 Xti 2019 & 536 & . & $97 \mathrm{CAl}$ & . \\
\hline 4 & 4 Xti 2019 & 213 & . & $33 \mathrm{CA}$ & . \\
\hline s. & 5 X1ti 2019 & Iffo & . & $12 \mathrm{CA}$ & . \\
\hline 6. & 6 Xtci 2019 & 655 & . & $193 \mathrm{CB}$ & . \\
\hline 7. & 7Xti 2019 & 572 & . & $110 \mathrm{~GB}$ & . \\
\hline 2. & 9 X1ti 2019 & 645 & . & $120 \mathrm{~GB}$ & . \\
\hline 2. & 9 Mari 2019 & 610 & . & $193 \mathrm{CB}$ & . \\
\hline 10 & In Xtsi 2019 & 530 & . & $110 \mathrm{CB}$ & . \\
\hline i1. & II Xtei 2019 & 200 & . & $3 \mathrm{BCAB}$ & . \\
\hline 12 & 12 XtEi 2019 & 145 & . & $17 \mathrm{cal}$ & . \\
\hline 1s. & 13 Xtei 2019 & GAT & . & $170 \mathrm{CB}$ & . \\
\hline 14. & 14 Xtei 2019 & Gis & . & $198 \mathrm{~GB}$ & . \\
\hline 15. & 15 Xtti 2019 & 535 & . & $190 \mathrm{~GB}$ & . \\
\hline 16 & 16 Xtei 2019 & SOT & . & $139 \mathrm{~GB}$ & - \\
\hline 17. & 17 Xtei 2019 & 521 & . & $1 \$ \mathrm{~GB}$ & . \\
\hline 12. & 18 Xtei 2019 & 181 & . & $49 \mathrm{~cm}$ & . \\
\hline 12. & 19 Xtei 2019 & 178 & . & $24 \mathrm{CAB}$ & . \\
\hline 20. & 20 Xtei 2019 & 665 & . & $170 \mathrm{~GB}$ & . \\
\hline 21. & 21 X1ti 2019 & +42 & . & $120 \mathrm{~GB}$ & . \\
\hline 22 & 22 Xtti 2019 & 445 & . & $120 \mathrm{~GB}$ & . \\
\hline 22. & 23 Xtei 2019 & 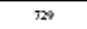 & . & LคA $\mathrm{CB}$ & . \\
\hline 24 & 24 Xtti 2019 & 59 & . & $19 \mathrm{CB}$ & . \\
\hline 25. & 25 NAti 2019 & 251 & . & $61 \mathrm{CA}$ & . \\
\hline 26. & 26 Xtti 2019 & 174 & . & $2 \mathrm{BCA}$ & . \\
\hline 27. & 27 Xtei 2019 & 651 & . & $100 \mathrm{~GB}$ & . \\
\hline $2 \mathrm{E}$ & 28 X1ti 2019 & 675 & . & $200 \mathrm{CB}$ & . \\
\hline 22. & 29 Xtei 2019 & 535 & . & $139 \mathrm{~GB}$ & . \\
\hline 30. & 30 Xt:i 2019 & S0T & . & $139 \mathrm{~GB}$ & . \\
\hline 31 . & 31 XE 2019 & 344 & . & $95 \mathrm{CA}$ & . \\
\hline
\end{tabular}

Tabel 5. Juli 2019

\begin{tabular}{|c|c|c|c|c|c|}
\hline \multirow{2}{*}{ No } & \multirow{2}{*}{ TANGGAL } & \multicolumn{2}{|c|}{ CLIENT } & \multicolumn{2}{|c|}{ TRAFFIC } \\
\hline & & ALL USERS & $\begin{array}{c}\text { USER } \\
\text { DETAIL }\end{array}$ & ALL USERS & $\begin{array}{c}\text { USER } \\
\text { DETAII }\end{array}$ \\
\hline 1 & 1 ЛLI 2019 & 665 & - & $170 \mathrm{~GB}$ & - \\
\hline 2. & $2 \pi L I 2019$ & 572 & - & $110 \mathrm{~GB}$ & - \\
\hline 3. & 3 ЛLL 2019 & 646 & - & $120 \mathrm{~GB}$ & - \\
\hline 4. & 4 ЛLI 2019 & 575 & - & $100 \mathrm{~GB}$ & - \\
\hline 5. & $5 \pi$ Л 2019 & 536 & - & $97 \mathrm{~GB}$ & - \\
\hline 6. & $6 \pi / \mathrm{L} 2019$ & 231 & - & $33 \mathrm{~GB}$ & - \\
\hline 3. & 7 ЛLI 2019 & 169 & - & $12 \mathrm{~GB}$ & - \\
\hline 8. & $8 \pi$ JLI 2019 & 657 & - & $140 \mathrm{~GB}$ & - \\
\hline 9 & 9 ЛLI 2019 & 572 & - & $110 \mathrm{~GB}$ & - \\
\hline 10 & $10 \pi \mathrm{RI} 2019$ & 646 & - & $120 \mathrm{CB}$ & - \\
\hline 11. & 11 תILI 2019 & 610 & - & $140 \mathrm{~GB}$ & - \\
\hline 12. & 12 JUI 2019 & 530 & - & $110 \mathrm{CB}$ & - \\
\hline 13. & 13 ЛUL 2019 & 220 & - & $38 \mathrm{~GB}$ & - \\
\hline 14. & 14 JULI 2019 & 147 & - & $17 \mathrm{~GB}$ & - \\
\hline 15. & 15 JUL 2019 & 647 & - & $170 \mathrm{~GB}$ & - \\
\hline 16. & 16 JUI 2019 & 669 & - & $180 \mathrm{~GB}$ & - \\
\hline 17. & 17 JULI 2019 & 535 & - & $130 \mathrm{~GB}$ & - \\
\hline 18. & $18 \pi$ JLI 2019 & 507 & - & $130 \mathrm{~GB}$ & - \\
\hline 19. & 19 JULI 2019 & 523 & - & $180 \mathrm{~GB}$ & - \\
\hline 20. & 20 JUL 2019 & 183 & - & $49 \mathrm{~GB}$ & - \\
\hline 21. & 21 ЛULI 2019 & 179 & - & $24 \mathrm{~GB}$ & - \\
\hline 22. & $22 \pi$ JI 2019 & 665 & - & $170 \mathrm{~GB}$ & - \\
\hline 23. & 23 JUL 2019 & 442 & - & $120 \mathrm{~GB}$ & \\
\hline 24. & $24 \pi$ JLI 2019 & 446 & - & $120 \mathrm{~GB}$ & - \\
\hline 25. & $25 \pi \mathrm{JII} 2019$ & 729 & - & $160 \mathrm{~GB}$ & - \\
\hline 26. & 26 JUI 2019 & 599 & - & $180 \mathrm{~GB}$ & - \\
\hline 27. & 27 תLI 2019 & 251 & - & $61 \mathrm{~GB}$ & - \\
\hline 28. & 28 ЛUI 2019 & 174 & - & $28 \mathrm{~GB}$ & - \\
\hline 29. & 29 JUL 2019 & 651 & - & $190 \mathrm{~GB}$ & - \\
\hline 30. & 30 JUL 2019 & 677 & - & $200 \mathrm{~GB}$ & - \\
\hline
\end{tabular}

Tabel 4. Juni 2019

\begin{tabular}{|c|c|c|c|c|c|}
\hline \multirow{2}{*}{ No } & \multirow{2}{*}{ TANGGAL } & \multicolumn{2}{|c|}{ CLIENT } & \multicolumn{2}{|c|}{ TRAFFIC } \\
\hline & & ALL USERS & $\begin{array}{c}\text { CSER } \\
\text { DETAII }\end{array}$ & $\begin{array}{l}\text { AIII } \\
\text { USERS }\end{array}$ & $\begin{array}{l}\text { USER } \\
\text { DETAII }\end{array}$ \\
\hline 1 & 1 תNI 2019 & 220 & - & $38 \mathrm{~GB}$ & - \\
\hline 2. & 2 ЛUN 2019 & 147 & - & $17 \mathrm{~GB}$ & - \\
\hline 3. & 3 JNI 2019 & 647 & - & $170 \mathrm{~GB}$ & - \\
\hline 4. & 4 ЛNI 2019 & 669 & - & $180 \mathrm{~GB}$ & - \\
\hline 5. & 5 ЛUN 2019 & 535 & - & $130 \mathrm{CB}$ & - \\
\hline 6. & 6 ЛUN 2019 & 507 & - & $130 \mathrm{CB}$ & - \\
\hline 3. & 7 ЛतN 2019 & 523 & - & $180 \mathrm{~GB}$ & - \\
\hline s. & 8 ת IN 2019 & 183 & - & $49 \mathrm{~GB}$ & - \\
\hline 9. & 9 9 & 179 & - & $24 \mathrm{~GB}$ & - \\
\hline 10. & $10 \pi \mathbb{N} 2019$ & 665 & - & $170 \mathrm{~GB}$ & - \\
\hline 11. & 11 ЛNI 2019 & 442 & - & $120 \mathrm{CB}$ & - \\
\hline 12. & 12 ЛN 2019 & 446 & - & $120 \mathrm{~GB}$ & - \\
\hline 13. & 13 JNI 2019 & 729 & - & $160 \mathrm{~GB}$ & - \\
\hline 14. & 14 JNI 2019 & 599 & & $180 \mathrm{~GB}$ & - \\
\hline 15 & 15 Лता 2019 & 251 & - & $61 \mathrm{~GB}$ & - \\
\hline 16. & 16 ЛN 2019 & 169 & - & $12 \mathrm{~GB}$ & - \\
\hline 17. & 17 ЛN 2019 & 657 & - & $140 \mathrm{~GB}$ & - \\
\hline 18. & 18 ЛN 2019 & 572 & - & $110 \mathrm{~GB}$ & - \\
\hline 19 & 19 ЛNI 2019 & 646 & - & $120 \mathrm{~GB}$ & - \\
\hline 20. & $20 \pi \mathbb{N} 2019$ & 610 & - & $140 \mathrm{~GB}$ & - \\
\hline 21. & 21 ЛN 2019 & 530 & - & $110 \mathrm{~GB}$ & - \\
\hline 22. & 22 ЛN 2019 & 220 & - & $38 \mathrm{~GB}$ & - \\
\hline 23. & $23 \pi \mathbb{N} 2019$ & 147 & - & $17 \mathrm{~GB}$ & - \\
\hline 24. & 24 ЛNI 2019 & 647 & - & $170 \mathrm{CB}$ & - \\
\hline 25. & $25 \pi \mathbb{N} 2019$ & 669 & - & $180 \mathrm{~GB}$ & - \\
\hline 26. & 26 ЛN 2019 & 535 & - & $130 \mathrm{~GB}$ & - \\
\hline 27. & 27 תल 2019 & 507 & - & $130 \mathrm{CB}$ & - \\
\hline 28. & 28 ЛNI 2019 & 523 & - & $180 \mathrm{~GB}$ & - \\
\hline 20. & $29 \pi \mathbb{N} 2019$ & 183 & - & $49 \mathrm{~GB}$ & - \\
\hline 30. & 30 ЛN 2019 & 154 & $\begin{array}{c}64 \\
\text { \{FTLT1.102) }\end{array}$ & $22 \mathrm{~GB}$ & $\begin{array}{c}\text { 13GB } \\
\text { (FT:Tl.102) }\end{array}$ \\
\hline
\end{tabular}

Tabel 6. Agustus 2019

\begin{tabular}{|c|c|c|c|c|c|}
\hline & & ALL USERS & $\begin{array}{l}\text { USER } \\
\text { DETAIL }\end{array}$ & ALL USERS & $\begin{array}{l}\text { USER } \\
\text { DETAIL }\end{array}$ \\
\hline 1 & 1 AGUSTUS 2019 & 681 & - & $200 \mathrm{~GB}$ & - \\
\hline 2. & 2 AGUSTUS 2019 & 564 & - & $150 \mathrm{CB}$ & - \\
\hline 3. & 3 AGUSTUS 2019 & 192 & - & $49 \mathrm{~GB}$ & - \\
\hline 4. & 4 AGUSTUS 2019 & 0 & - & $2.1 \mathrm{~GB}$ & $\begin{array}{c}110 \mathrm{~KB} \\
\text { (FTRDOSEN) }\end{array}$ \\
\hline 5. & 5 AGUSTUS 2019 & 647 & - & $170 \mathrm{~GB}$ & - \\
\hline 6. & 6 AGUSTUS 2019 & 669 & - & $180 \mathrm{~GB}$ & - \\
\hline 3. & 7 AGUSTUS 2019 & 535 & - & $130 \mathrm{~GB}$ & - \\
\hline 8. & 8 AGUSTUS 2019 & 507 & - & $130 \mathrm{CB}$ & - \\
\hline 9. & 9 AGUSTUS 2019 & 523 & - & $180 \mathrm{CB}$ & - \\
\hline 10. & 10 AGUSTUS 2019 & 183 & - & $49 \mathrm{~GB}$ & - \\
\hline 11. & 11 AGUSTUS 2019 & 179 & - & $24 \mathrm{~GB}$ & - \\
\hline 12. & 12 AGUSTUS 2019 & 665 & - & $170 \mathrm{~GB}$ & - \\
\hline 13. & 13 AGUSTUS 2019 & 442 & - & $120 \mathrm{~GB}$ & 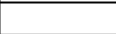 \\
\hline 14. & 14 AGUSTUS 2019 & 446 & - & $120 \mathrm{~GB}$ & - \\
\hline 15 & 15 AGUSTUS 2019 & 729 & - & $160 \mathrm{~GB}$ & - \\
\hline 16. & 16 AGUSTUS 2019 & 599 & 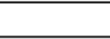 & $180 \mathrm{~GB}$ & - \\
\hline 17. & 17 AGUSTUS 2019 & 251 & - & $61 \mathrm{~GB}$ & - \\
\hline 18. & 18 AGUSTUS 2019 & 174 & - & $28 \mathrm{~GB}$ & - \\
\hline 19 & 19 AGUSTUS 2019 & 651 & - & $190 \mathrm{CB}$ & - \\
\hline 20. & 20 AGUSTUS 2019 & 677 & - & $200 \mathrm{~GB}$ & - \\
\hline 21. & 21 AGUSTUS 2019 & 646 & - & $120 \mathrm{~GB}$ & - \\
\hline 22. & 22 AGUSTUS 2019 & 610 & - & $140 \mathrm{~GB}$ & - \\
\hline 23. & 23 AGUSTUS 2019 & 530 & - & $110 \mathrm{~GB}$ & - \\
\hline 24. & 24 AGUSTUS 2019 & 220 & - & $38 \mathrm{~GB}$ & - \\
\hline 25. & 25 AGUSTUS 2019 & 147 & - & $17 \mathrm{~GB}$ & - \\
\hline 26. & 26 AGUSTUS 2019 & 647 & - & $170 \mathrm{~GB}$ & - \\
\hline 27. & 27 AGUSTUS 2019 & 669 & - & $180 \mathrm{CB}$ & - \\
\hline 28. & 28 AGUSTUS 2019 & 535 & - & $130 \mathrm{CB}$ & - \\
\hline 29. & 29 AGUSTUS 2019 & 507 & - & $130 \mathrm{~GB}$ & - \\
\hline 30. & 30 AGUSTUS 2019 & 523 & - & $180 \mathrm{CB}$ & - \\
\hline 31. & 31 AGUSTUS 2019 & 329 & $\begin{array}{c}115 \\
\text { (FTLT1.102) }\end{array}$ & $50 \mathrm{~GB}$ & $\begin{array}{c}20 \mathrm{~GB} \\
\text { (FT.LT1.102) }\end{array}$ \\
\hline
\end{tabular}


Jurnal Teknologi dan Manajemen Industri, Vol. 6 No. 2, Agustus 2020

Pascasarjana Institut Teknologi Nasional Malang

Tabel 7. Pengujian Normalitas

\begin{tabular}{|l|l|r|r|}
\hline & & \multicolumn{1}{|c|}{ Sebelum (MJ } & Sesudah (JA) \\
\hline $\mathrm{N}$ & & 31 & 31 \\
\hline Parameter & Mean & 460,306 & 559,629 \\
\hline & Std. Deviation & 116,2616 & 87,4884 \\
\hline Most Extreme & Absolute &, 156 &, 168 \\
\hline Differences & Positive &, 147 &, 088 \\
\hline & Negative &,- 156 &,- 168 \\
\hline Kolmogorov & &, 871 &, 937 \\
Smirnov & & &, 344 \\
\hline Sig (2 tailed) & &, 434 &, \\
\hline
\end{tabular}

a. Distribution is normal

Sig $=0,434>0,05$ dan 0,344 >0,05 berarti sebaran datanya normal.

\section{T-Test}

Tabel 8. Paired Sample

\begin{tabular}{|c|c|c|c|c|c|}
\hline & Mean & N & $\begin{array}{c}\text { Std. } \\
\text { Deviation }\end{array}$ & $\begin{array}{c}\text { Std. Error } \\
\text { Mean }\end{array}$ \\
\hline Pair & Sebelum (MJ) & 460.306 & 31 & 116,2616 & 20,8812 \\
\hline 1 & Sesudah (JA) & 559,629 & 31 & 87,4884 & 15,7134 \\
\hline
\end{tabular}

Tabel 9. Paired Correlations

\begin{tabular}{|c|c|c|c|c|}
\hline & & N & Correlation & Sig. \\
\hline $\begin{array}{c}\text { Pair } \\
1\end{array}$ & $\begin{array}{c}\text { Sebelum (MJ) \& } \\
\text { Sesudah (JA) }\end{array}$ & 31 &,- 357 & 0,48 \\
\hline
\end{tabular}

Tabel 10. Paired Samples Test

\begin{tabular}{|c|c|c|c|c|c|c|c|c|c|}
\hline & & \multirow[t]{2}{*}{ Mean } & \multirow[t]{2}{*}{ Std. Deviation } & \multirow[t]{2}{*}{$\begin{array}{l}\text { Std. Error } \\
\text { Mean }\end{array}$} & \multicolumn{2}{|c|}{$\begin{array}{l}95 \% \text { Confidence Interval of } \\
\text { the Difference }\end{array}$} & \multirow[t]{2}{*}{$\mathrm{T}$} & \multirow[t]{2}{*}{$\mathrm{df}$} & \multirow[t]{2}{*}{$\begin{array}{l}\text { Sig. (2- } \\
\text { tailed) }\end{array}$} \\
\hline & & & & & Lower & Upper & & & \\
\hline $\begin{array}{c}\text { Pair } \\
1\end{array}$ & $\begin{array}{l}\text { Sebelum (MJ) - } \\
\text { Sesudah (JA) }\end{array}$ & $-99,323$ & 168,6423 & 30,2890 & $-161,181$ & $-37,464$ & $-3,279$ & ,003 & 30 \\
\hline
\end{tabular}

Dengan diberikan fasilitas baru penambahan hotspot terjadi peningkatan sebesar 99,323, peningkatan sebesar itu secara statistic bisa dikatakan benar-benar meningkat maka diperoleh nilai $\mathrm{t}$ sebesar $-3,279$ dengan nilai sig= 0,003 $<0,05$ berarti ada perbedaan. Bisa disimpulkan bahwa harus diberikan fasilitas tambahan mempengaruhi peningkatan rata-rata pemakaian sebesar 99,323 dimana peningkatan yang terjadi antara 37,464 sd 161,181.

\section{Kesimpulan}

Berdasarkan proses perancangan, pengujian dan pembahasan hasil dapat ditarik beberapa kesimpulan sebagai berikut.

a. Berdasarkan pengujian dengan SPSS terjadi peningkatan sebesar 99,323, peningkatan sebesar itu secara statistic bisa dikatakan benar-benar meningkat dengan nilai pengujian $\mathrm{t}$ sebesar $-3,279$, sig= $0,003<0,05$.

b. Tahap pertama dari penelitian ini adalah memperbaiki kebutuhan jaringan wifi telekomunikasi di ruang Dosen lantai 2 Fakultas Teknik, Kampus Limo dengan cara menambah akses poin yang dapat menjangkau semua pengguna di ruang Dosen lantai 2 tersebut.

c. Dengan adanya penambahan akses point tersebut, saat ini jaringan wifi pada ruang Dosen lantai 2, Fakultas Teknik, Kampus Limo dapat diakses dengan mudah dan lancar tanpa ada lagi kesulitan ataupun keterlambatan pengaksesan. 


\section{Daftar Pustaka}

[1] Haryanto, M. D., \& Riadi, I. 2014. Analisis dan Optimalisasi Jaringan Menggunakan Teknik Load Balancing: Studi Kasus Jaringan UAD Kampus 3. Jurnal Sarjana Teknik Informatika, 2(3), 172180.

[2] Rahmatillah, F., Usman, U. K., Riza, T. A. 2015. Analisis Performansi Traffic Offload Data Antara $3 \mathrm{~g}$ dan Wifi. e-Proceeding of Engineering, 2(1), 42-51.

[3] Rahman, T., Sumarna, Nurdin, H. 2020. Analisis Performa RouterOS MikroTik pada Jaringan Internet. Jurnal Inovtek Polbeng - Seri Informatika, 5(1), 178-192.

[4] Yola, M., \& Budianto, D. 2013. Analisis Kepuasan Konsumen Terhadap Kualitas Pelayanan dan Harga Produk pada Supermarket dengan Menggunakan Metode Importance Performance Analysis (IPA). Jurnal Optimasi Sistem Industri, 12(1), 301-309.

[5] Dharsono, W. W., Nursanti, E., \& Hutabarat, J. 2015. Pengaruh Kualitas Pelayanan Akademik Non-Akademik Citra Lembaga Terhadap Kepuasan dan Loyalitas Mahasiswa: Studi Kasus di Universitas Satya Wiyata Mandala Nabire. Jurnal Teknologi dan Manajemen Industri, 1(2), 28-35.

[6] Dimatteo, S., Hui, P., Han, B., \& Li, V. O. K. 2019. Cellular Traffic Offloading through Wifi Networks. $8^{\text {th }}$ IEEE International Conference on Mobile Adhoc and Sensor Systems (MASS), 192 201.

[7] Xue, C., Luo, J., Halfmann, R. Schulz, E., \& Hartmann, C. 2009. Inter GW Load Balancing for Next Generation Mobile Networks with Flat Architecture. 69 ${ }^{\text {th }}$ IEEE Vehicular Technology Conference, $1-5$.

[8] B. Han, P. Hui, V. S. A. Kumar, M. V. Marathe, G. Pei, \& A. Srinivasan. 2010. Cellular Traffic Offloading through Opportunistic Communications: A Case Study". Proceedings of the $5^{\text {th }}$ ACM workshop on Challenged networks, $31-38$.

[9] Ali, M. F., \& Khan, R. Z. 2012. The study on load balancing strategies in distributed computing system. International Journal of Computer Science \& Engineering Survey (IJCSES), 3(2), 19 30

[10] Jayamaha, N. P., Grigg, N. P., \& Mann, R. 2011. Empirical analysis of the Baldrige Criteria as organizational performance measure dan a theoretical model. Measuring Business Excellence, 15(1), 20-33. 